\title{
Mental health status and psychosocial issues during Nationwide COVID-19 quarantine in Iran in 2020: A cross-sectional study in Mazandaran Province
}

\author{
Maryam Hasannezhad Reskati ${ }^{1}$ - Misagh Shafizad ${ }^{2}$ - Mohsen Aarabi ${ }^{3}$ - Akbar Hedayatizadeh-Omran ${ }^{4}$. \\ Sahar Khosravi ${ }^{5}$. Forouzan Elyasi ${ }^{6,7,8}$ (D)
}

Accepted: 15 June 2021 / Published online: 7 July 2021

(C) The Author(s), under exclusive licence to Springer Science+Business Media, LLC, part of Springer Nature 2021

\begin{abstract}
The coronavirus disease 2019 (COVID-19) pandemic is spreading rapidly, and its psychosocial impact remains a big challenge. In this respect, quarantine has been recommended, as a significant practice, to prevent the given condition. Therefore, the present study was to determine the prevalence rates of depression, anxiety, and stress and to reflect on the impact of COVID-19, as a traumatic stressor event, on individuals. This web-based survey was fulfilled via an online questionnaire, completed by respondents selected through the cluster sampling technique, from March 24 to April 10, 2020, living in Mazandaran Province, Northern Iran. Accordingly, the data regarding demographic characteristics, physical health status, quarantine compliance, contact with COVID-19, and additional information were collected. The psychosocial impact of the pandemic was then assessed by the Impact of Event Scale-Revised (IES-R), and the respondents' mental health status was evaluated using the Depression, Anxiety, and Stress Scale-21 (DASS-21). Data analysis was further performed by linear regression. The study findings, from 1075 respondents, revealed that $22.5 \%$ of the cases had moderate-to-severe depression, $38.5 \%$ of the individuals were suffering from moderate-to-severe anxiety, and $47.2 \%$ of the participants were experiencing moderate-to-severe stress. In $14.5 \%$ of the respondents, the psychosocial impact of COVID-19 also varied from the possibility of post-traumatic stress disorder (PTSD) to immunosuppression $(p<0.01)$. With the high prevalence rates of depression, anxiety, and stress, mental health professionals are suggested to develop psychosocial interventions and support plans for the general population to reduce the impact of the COVID19 pandemic on public mental health status.
\end{abstract}

Keywords Anxiety $\cdot$ COVID-19 $\cdot$ Depression $\cdot$ Impact of event $\cdot$ Stress

\section{Introduction}

In late 2019, a novel type of coronavirus, associated with the cluster of pneumonia cases, was reported in Wuhan, Hubei Province, China. The virus spread rapidly across this country and became a pandemic (World Health Organization [WHO],

Forouzan Elyasi

forouzan.elyasi@gmail.com; F.elyasi@mazums.ac.ir

1 Educational Psychology, Mazandaran University of Medical Sciences, Sari, Iran

2 Orthopedic Research Center, Mazandaran University of Medical Science, Sari, Iran

3 Department of Family Medicine, School of Medicine, Mazandaran University of Medical Sciences, Sari, Iran

4 Gastrointestinal Cancer Research Center, Mazandaran University of Medical Sciences, Sari, Iran
, 2020a). Iran's officials also reported the first case of coronavirus disease 2019 (COVID-19), confirmed in February 2020, in the city of Qom (Yavarian et al., 2020). As of September 20, 2020, more than 30 million people worldwide have been diagnosed with COVID-19, according to the WHO. On the same date, the number of people affected in Iran has been

5 Hematology and Medical Oncology Fellowship, Hematology, HSCT and Cancer Shariatic Hospital Research Center, Tehran University of Medical Sciences, Tehran, Iran

6 Psychiatry and Behavioral Sciences Research Center, Sexual and Reproductive Health Research Center, Addiction Institute, Mazandaran University of Medical Sciences, Sari, Iran

7 Consultation-Liaison Psychiatry Ward, Imam Khomeini General Hospital, Razi Ave., Sari, Mazandaran, IR 48157-33971, Iran

8 Department of Psychiatry, School of Medicine, Mazandaran University of Medical Sciences, Sari, Iran 
419,043 , and more than 24,000 deaths have been so far recorded (WHO, , 2020b). Due to the growth trajectory of the COVID-19 transmission, occurring mainly through airborne droplets and close contacts (The Center for Disease and Prevention [CDC], , 2020a), the WHO has recommended actions, focused on preventing the COVID-19 prevalence, in different countries. Such preventive measures take account of implementing a series of quarantine practices to restrict travels, isolate healthy people exposed to the virus in order to monitor their symptoms, and ensure early detection of the disease. Here, quarantine should not be taken mistakenly with the definition of isolation that implies the separation of healthy people from infected cases (WHO, , 2020c). Iranian government also decided to quarantine people and close most sectors during the Persian New Year holidays in March 2020 (Seddighi et al., 2020). More traffic was thus imposed on Mazandaran, one of the Northern Provinces as a holiday destination, with a high prevalence rate of COVID-19 (Moghanibashi-Mansourieh, 2020a).

Although patient quarantine and isolation aim to protect individuals against infectious diseases, it is imperative to consider mental health consequences in cases experiencing such restrictions. For example, in April 2020, the prevalence rate of post-traumatic stress disorder (PTSD) to immunosuppression (PTSD) in 603 Tunisians had been estimated at 33\% (FekihRomdhane et al., 2020). In similar results, reported among 2286 Italians during the COVID-19 outbreak, the PTSD rate had been 29.5\% (Forte et al., 2020). According to the available sources, the experience of life-threatening physical illnesses, such as COVID-19, can be a cause for the PTSD symptoms (Sun et al., 2020), including chronic anxiety with re-experiences of traumatic events, flashbacks, increased arousal, and nightmares (Dutheil et al., 2020). In addition, people with PTSD are at higher risk of suicides (Thibodeau et al., 2013). Several studies have accordingly reported the incidence of PTSD among the general population, health care workers, and patients during the outbreaks of the virus (Lee et al., 2019; Chang \& Park, 2020; Park et al., 2020; Wang et al., 2020a). According to a study conducted one month after the COVID-19 pandemic, factors such as female gender, living in a city affected with COVID-19, poor sleep quality, and previous experience of exposure to an infected body could be significantly associated with PTSD severity (Sun et al., 2020).

About other psychological disorders during the COVID-19 pandemic, the prevalence rates of stress, anxiety, and depression were $34 \%, 26 \%$, and $26 \%$, respectively (Krishnamoorthy et al., 2020). Other surveys had further confirmed these findings (Wang et al., 2020b).

In a study in Iran, 10,754 people had been surveyed online from March 1 to 9, 2020, and the results had shown that anxiety in women, the people following most news related to COVID-19, and the age group of 21-40 years, was at a higher level. Finally, the level of anxiety had been reported significantly higher among people with at least one family member, relative, or friend suffering from COVID-19. In this study, only the level of anxiety had been assessed and the medical staff had not been included as respondents (Moghanibashi-Mansourieh, 2020b). A review study in Iran had also found no difference between men and women. In this respect, the prevalence rates of stress, anxiety, and depression, as a result of the epidemic in a general population, had been reported at $29.6 \%, 31.9 \%$, and $33.7 \%$, respectively (Salari et al., 2020). Although the risk of COVID-19 transmission is the same for all age groups, its lethal effect increases significantly with age (Yildirim et al., 2021). Studies have also reported that the risk of progression and mortality in the elderly is more significant (Novel, 2020). From June 24 to 30, 2020, out of 5412 adults living across the United States as well as 933 participants aged 65 and over had shown a significant percentage of anxiety (6.2\%), depression (5.8), and traumaor stress-related disorder (TSRD) (9.2\%), compared with those in younger age groups (Czeisler et al., 2020). Correspondingly, a cross-sectional study of 3840 people, aged 18-80, in Spain, had revealed that older people (80-60 years) had lower rates of anxiety, depression, and PTSD than younger cases (40-59 years) (González-Sanguino et al., 2020). Other studies had further shown that the mental health status of young people, compared with that of adults, had been often disproportionately affected by traumatic events (Danese et al., 2020).

In a survey of 1210 people in 194 Chinese cities, $53.8 \%$ of the respondents had harmoniously reported moderate-tosevere psychosocial impact, $16.5 \%$ of the individuals had shown moderate-to-severe depression, $28.8 \%$ of the cases were suffering from moderate-to-severe anxiety, and $8.1 \%$ of the participants had reported moderate-to-severe stress (Wang et al., 2020b).

Consistent results in numerous studies can explain the reason behind experiencing different mental health conditions during quarantine or isolation (Zhang et al., 2020a). Based on the previous studies and the COVID-19 outbreak in Mazandaran Province, Iran, the prevalence rates of anxiety, depression, stress, and the effect of this pandemic as a traumatic event were investigated. In addition, the relationship between these variables and gender, age, marital status, occupation, level of education, physical health status, and a history of contact with a person with suspected or confirmed COVID19 , etc. following the pandemic progression among people living in Mazandaran Province, Northern Iran, were examined during home quarantine.

\section{Participants and Procedure}

Using an anonymous online questionnaire, a descriptiveanalytical cross-sectional research design was employed to assess the immediate psychosocial responses of the 
quarantined population during the COVID-19 outbreak. Following the quarantine during the Persian New Year holidays, schools were closed, national screening was conducted, people were encouraged to quarantine themselves, and the number of those involved in service jobs was reduced by a third (Doshmangir et al., 2020). The present study was a survey and the sampling was implemented, focusing on the residents of Mazandaran Province, Northern Iran. The online questionnaire was also created through groups and channels on social media, and the respondents were asked to share it with other people.

The inclusion criteria were the cases living in Mazandaran Province, with no COVID-19 infection, undergoing quarantine (Of note, the data were collected at the first peak of the pandemic. It was not also possible to collect the questionnaires at patient bedside due to a lack of personal protective equipment. Moreover, given the insufficient laboratory kits, selfreporting by the patients could not be cited, so they were excluded). The exclusion criteria were related to the respondents returning incomplete questionnaires and the individuals who were not living in Mazandaran Province.

The Persian version of the questionnaire was completed using an online platform, developed by Sadra Rayaneh Novin Tabarestan Engineering Co., based in Mazandaran Province, Iran. The study approval was also obtained from the Research Ethics Committee of Mazandaran University of Medical Sciences, Mazandaran, Iran, as published on the website of the National Ethics Committee (IR.MAZUMS.REC.1399.001). An informed consent form for data use was further acquired from the respondents, and they were ensured that their information would remain confidential. Finally, the data collection was carried out from March 24 to April 10, 2020.

\section{Survey Development}

Several surveys have been so far conducted on the psychosocial impact of severe acute respiratory syndrome (SARS) and the flu on patients (Rubin et al., 2010; Leung et al., 2003; Leung et al., 2009). Thus, several items regarding the onset of the COVID-19 outbreak were added to the existing questionnaire, covering a variety of areas, including demographic characteristics information, clinical psychiatric symptoms, healthcare services, a history of contact with cases with suspected or confirmed COVID-19, quarantine status, medical history, beliefs about COVID-19 and its treatment, and the like.

The demographic characteristics information was associated with age, gender, having a child older or younger than 16, marital status, family size, occupation, place of living, level of education, clinical psychiatric symptoms such as coughing, shortness of breath, and dizziness for at least one day, and a history of chronic diseases. The variables, related to the use of healthcare services over the last 14 days, were comprised of visits by a physician, having COVID-19 tests, and health insurance coverage. Contact history was also concerned with direct and indirect exposure to cases with suspected or confirmed COVID-19. Besides, the quarantine variables, in the last 14 days, were those ordered by a physician or practiced voluntarily at home. As well, beliefs about COVID-19 included the ones concerned with increasing rates of COVID-19 spread, mortality, and treatment. Insomnia over the last 14 days and a history of taking sleeping pills, as well as the sources of information about COVID-19 were additionally recorded.

\section{Measures}

\section{The Impact of Event Scale-Revised (IES-R)}

The IES-R was used to evaluate the psychosocial impact of quarantine during the COVID-19 pandemic. This self-report measure consisted of 22 items, in which the respondents could provide answers based on a five-point Likert-type scale, ranging from 0 to 4 . The total ranking score was from 0 to 88 . A score of 24 or higher was thus clinically significant (Asukai et al., 2002), indicating that the respondents had no full (viz. severe) PTSD and had partial PTSD or at least some of its symptoms. A score of 33 or higher was accordingly the best cutoff value for a probable diagnosis of PTSD (Creamer et al., 2003), and a score of 37 or higher could be adequate to show immunosuppression (Kawamura et al., 2001).

In a study by Panaghi et al., the validity and the reliability of the Persian version of the IES-R had been already confirmed. The overall Cronbach's alpha coefficients had been correspondingly determined at 0.887 and 0.86 , in groups of 10-20 and above 20 years of age, respectively. The Persian version of the IES-R also had strong internal consistency and test-retest reliability (Panaghi et al., 2006).

\section{The Depression, Anxiety, and Stress Scale-21 (DASS-21)}

The DASS-21 was employed to evaluate the respondents' mental health status (Brown et al., 1997). This questionnaire contained 21 items, with three subscales of depression, anxiety, and stress. In this sense, the depression subscale was comprised of seven items, yielding a total score ranging from 0 to 42 , wherein the ones with a score above 28 were identified with highly severe depression. The anxiety subscale also encompassed seven items with a similar total score, and the ones with a score above 20 , could be characterized by extremely severe anxiety. Finally, the stress subscale included seven items with a similar total score, and the ones with a score above 35 , suggested highly severe stress. In a study by Sahebi et al., the validity and the reliability of the Persian version of the DASS-21 had been already confirmed. The Cronbach's alpha coefficient, as an internal consistency 
measure, had been further determined for the DASS-21 subscales. Thus, the Cronbach's alpha coefficients of 0.77, 0.79, and 0.78 had been calculated for the depression, anxiety, and stress subscales, respectively (Sahebi et al., 2005).

\section{Statistical Analysis}

The sample size was determined according to the following formula:

$n=\frac{Z^{2} P(1-P)}{d^{2}}$

Where the $\mathrm{CI}(Z)$ was $95 \%$, the prevalence rate of COVID$19(P)$ was estimated at $50 \%$ since its exact value needed to be determined in Iran, and accuracy $(d)$ was set at $5 \%$. As a percentage of the variables might have been lost during the observation period, the final sample size was considered by $1000-1200$ individuals.

In this study, a descriptive statistical method was used to analyze the data collected from the variables, including demographic characteristics, clinical psychiatric symptoms, healthcare services, a history of contacts with cases with confirmed or suspected COVID-19, quarantine compliance, and medical history. The response rate was further calculated based on the number of the respondents for each item and the total number of the answers. In this study, linear regression was exercised to determine the relationships between the variables, i.e., demographic characteristics, healthcare services, a history of contacts, quarantine compliance, medical history, and health-related variables, or the scores obtained from the IES-R and the DASS-21 subscales. The SPSS Statistics software (ver. 26) was ultimately utilized to carry out the statistical tests in this study, in which the significance level was considered at $p<0.05$.

\section{Results}

\section{Respondents}

Out of 2040 respondents, 1075 cases were eligible for inclusion in the present study. Other individuals had not adhered to quarantine or had been from other provinces. The demographic characteristics results are shown in Table 1.

The psychosocial impact of COVID-19 was further assessed using the IES-R, in which the respondents obtained a mean score of 29.71 (standard deviation $[\mathrm{SD}]=16.06$ ). Using this measure, 759 cases $(70.6 \%)$ were classified as normal individuals, 160 respondents (14.9\%) were identified with partial PTSD, 37 individuals (3.4\%) were ranked with probable PTSD, and 119 participants (11.1\%) were characterized as full PTSD to the point of immunosuppression.
In the depression subscale of the DASS-21, 742 respondents $(69.1 \%)$ were found normal, 90 cases $(8.4 \%)$ had mild depression, 105 individuals $(9.8 \%)$ were suffering from moderate depression, 96 cases (8.9\%) had been affected with severe depression, and 41 individuals (3.8\%) had highly severe depression. Considering the anxiety subscale, 580 respondents $(54.1 \%)$ were normal, 80 cases $(7.4 \%)$ had mild anxiety, 188 individuals (17.5\%) suffered from moderate anxiety, 85 cases $(7.9 \%)$ had severe anxiety, and 141 respondents (13.1\%) were experiencing extremely severe anxiety. In the stress subscale, 742 cases $(40.5 \%)$ were normal individuals, 90 respondents $(12.3 \%)$ had mild stress, 105 individuals $(19.8 \%)$ were suffering from moderate stress, 96 cases $(13.3 \%)$ had severe stress, and 41 participants $(14.1 \%)$ were undergoing highly severe stress.

\section{Relationship between Demographic Variables, Depression, Anxiety, and Stress, and Impact of COVID- 19}

The relationships found between the demographic variables and the DASS-21 subscales (i.e., depression, anxiety, and stress) are presented in Table 2. The results regarding the stress subscale in the DASS-21, showed that the respondents, in the age groups of 18-30 and 31-40 years, had obtained significantly higher stress scores $(B=3.08,95 \%$ CI: 0.56 to 5.63 for the $18-30$ age group and $\mathrm{B}=3.12,95 \% \mathrm{CI}$ : 0.68 to 5.57 for the $31-40$ age group).

The results for the anxiety subscale of the DASS- 21 also demonstrated that men gained significantly lower anxiety scores $(\mathrm{B}=-1.38,95 \% \mathrm{CI},-2.55$ to -0.21$)$ and the individuals in the age group of $31-40$ years obtained higher anxiety scores (B $=2.37,95 \%$ CI: 0.43 to 4.31 ).

The results regarding the depression subscale of the DASS21 additionally revealed that men had significantly lower depression scores $(\mathrm{B}=-1.38,95 \% \mathrm{CI},-2.55$ to -0.21$)$ and the individuals in the age groups of $18-30$ and $31-40$ acquired significantly higher depression scores $(B=3.80,95 \%$ CI: 1.39 to 6.22 for the $18-30$ age group, and $\mathrm{B}=2.76,95 \% \mathrm{CI}: 0.43$ to 5.08 for the $31-40$ age group).

The relationships between the demographic variables and the severity of COVID-19 as well as those between the given variables and the scores in the IES-R subscales are respectively shown in Tables 2 and 3.

The results established a significant relationship between the scores in the subscales of the IES-R and gender $(p<$ 0.001). A major portion of men (38\%) also scored above 37 on this scale, classified as severe COVID-19 to the point of immunosuppression. In contrast, a significant part of women (49\%) obtained normal IES-R scores. Overall, men had significantly higher scores on this scale $(\mathrm{B}=-5.98,95 \% \mathrm{CI}$ : -8.10 to -3.85 ). 
Table 1 Demographic variables following COVID-19 outbreak

\begin{tabular}{|c|c|c|c|}
\hline Variables & & Frequency & Percentage \\
\hline \multirow[t]{2}{*}{ Gender } & Male & 778 & $72.4 \%$ \\
\hline & Female & 297 & $27.6 \%$ \\
\hline \multirow[t]{5}{*}{ Age } & $18-30$ & 309 & $28.7 \%$ \\
\hline & $31-40$ & 442 & $41.1 \%$ \\
\hline & $41-50$ & 208 & $19.3 \%$ \\
\hline & $51-60$ & 95 & $8.8 \%$ \\
\hline & Over 60 & 21 & $2.0 \%$ \\
\hline \multirow[t]{4}{*}{ Marital status } & Single & 286 & $26.6 \%$ \\
\hline & Married & 751 & $69.9 \%$ \\
\hline & Divorced & 34 & $3.2 \%$ \\
\hline & Deceased spouse & 4 & $0.4 \%$ \\
\hline \multirow[t]{4}{*}{ Level of education } & Primary school & 9 & $0.8 \%$ \\
\hline & High school diploma & 220 & $20.5 \%$ \\
\hline & Bachelor's and Master's degrees & 722 & $67.2 \%$ \\
\hline & $\mathrm{PhD}$ & 124 & 11.5 \\
\hline \multirow[t]{7}{*}{ Occupation } & Unemployed & 89 & $8.3 \%$ \\
\hline & Housewife & 300 & $27.9 \%$ \\
\hline & Student & 139 & $12.9 \%$ \\
\hline & Medical staff & 56 & $5.2 \%$ \\
\hline & Staff elsewhere & 291 & $27.1 \%$ \\
\hline & Worker & 131 & $12.2 \%$ \\
\hline & Healthcare worker & 69 & $6.4 \%$ \\
\hline \multirow[t]{4}{*}{ Children } & Under 16 & 401 & $37.3 \%$ \\
\hline & Over 16 & 188 & $17.5 \%$ \\
\hline & Both & 113 & $10.5 \%$ \\
\hline & Childless & 373 & $34.7 \%$ \\
\hline \multirow[t]{2}{*}{ Cough/Dizziness } & Yes & 230 & $21.4 \%$ \\
\hline & No & 845 & $78.6 \%$ \\
\hline \multirow[t]{2}{*}{ Examination } & Yes & 122 & $11.3 \%$ \\
\hline & No & 953 & $88.7 \%$ \\
\hline \multirow[t]{2}{*}{ COVID-19 test } & Yes & 73 & $6.8 \%$ \\
\hline & No & 1002 & $93.2 \%$ \\
\hline \multirow[t]{2}{*}{ Prescribed quarantine } & Yes & 107 & $10.0 \%$ \\
\hline & No & 968 & $90.0 \%$ \\
\hline \multirow[t]{2}{*}{ Self-quarantine } & Yes & 1068 & $99.3 \%$ \\
\hline & No & 7 & $0.7 \%$ \\
\hline \multirow[t]{2}{*}{ Chronic diseases } & Yes & 163 & $15.2 \%$ \\
\hline & No & 912 & $84.8 \%$ \\
\hline \multirow[t]{2}{*}{ Health insurance coverage } & Yes & 933 & $86.8 \%$ \\
\hline & No & 142 & $13.2 \%$ \\
\hline \multirow[t]{2}{*}{ Direct contact } & Yes & 98 & $9.1 \%$ \\
\hline & No & 976 & $90.9 \%$ \\
\hline \multirow[t]{2}{*}{ Indirect contact } & Yes & 229 & $21.3 \%$ \\
\hline & No & 845 & $78.7 \%$ \\
\hline \multirow[t]{2}{*}{ Suspected contact } & Yes & 249 & $23.2 \%$ \\
\hline & No & 825 & $76.8 \%$ \\
\hline
\end{tabular}




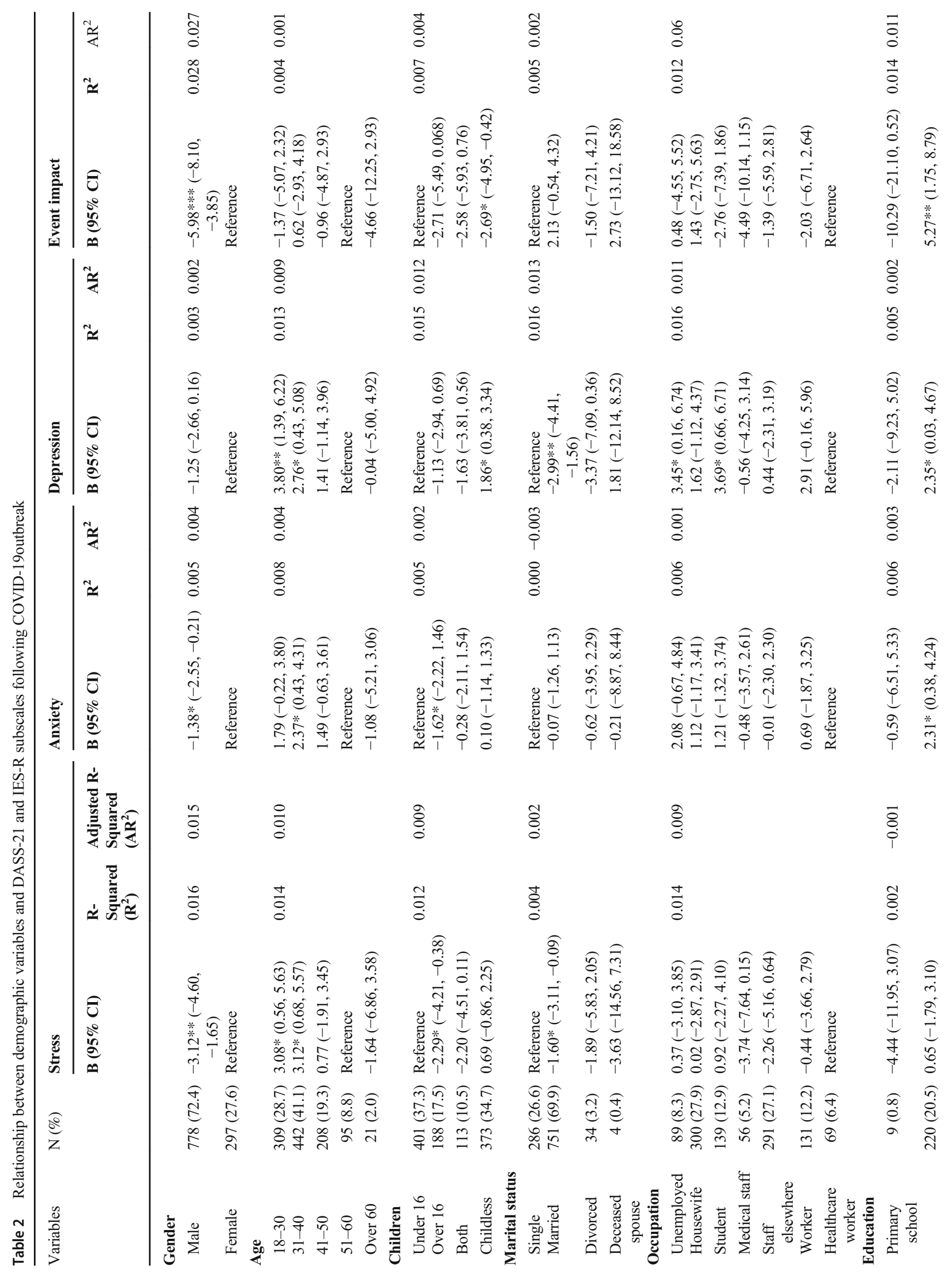


Relationship between DASS-21 and IES-R Scores, Physical Health Status, and a History of Contacts with COVID-19

As illustrated in Table 4, the linear regression outcomes showed that coughing, shortness of breath, and dizziness were significantly associated with higher scores in the stress subscale of the DASS-21 ( $\mathrm{B}=4.25,95 \%$ CI: 2.65 to 5.84). Coughing, shortness of breath, and dizziness were also significantly correlated with higher scores in the anxiety subscale of the DASS-21 ( $\mathrm{B}=3.95,95 \% \mathrm{CI}$ : 2.70 to 5.21).

Having a chronic disease (viz. diabetes, hypertension, heart and kidney disorders, cancer, etc.) was similarly found to be significantly associated with higher scores in the anxiety subscale of the DASS- $21(\mathrm{~B}=1.50,95 \% \mathrm{CI}$ : 0.4 to 2.96). Moreover, coughing, shortness of breath, and dizziness were significantly correlated with higher scores in the depression subscale of the DASS-21 ( $\mathrm{B}=3.33,95 \%$ CI: 1.80 to 4.85 ).

As shown in Tables 3 and 4, individuals with coughing, shortness of breath, and dizziness gained significantly higher total IES-R scores ( $\mathrm{B}=6.41,95 \% \mathrm{CI}$ : 4.10 to 8.73$)$. A significant relationship was further established between coughing, shortness of breath, and dizziness and the scores in the subscales of the IES-R $(p<0.001)$. Of the cases with these symptoms, $49.6 \%$ obtained scores above 37 (namely, PTSD to the point of immunosuppression).

As outlined in Table 4, the results for the stress subscale of the DASS-21 showed that people with a history of direct, indirect, or suspected contacts with a case with confirmed or suspected COVID-19 had significantly higher stress scores $(\mathrm{B}=3.15,95 \% \mathrm{CI}: 0.85$ to 5.45 for direct contact, $\mathrm{B}=2.26$, 95\%CI: 0.65 to 3.88 for indirect contact, and $\mathrm{B}=4.34,95 \%$ CI: 2.79 to 5.89 for suspected contact).

Besides, individuals with a history of direct, indirect, or suspected contacts with a case with confirmed or suspected COVID-19 had significantly higher scores in the anxiety subscale of the DASS-21 ( $\mathrm{B}=2.60,95 \% \mathrm{CI}$ : 0.78 to 4.41 for direct contact, $\mathrm{B}=1.91,95 \% \mathrm{CI}: 0.63$ to 3.18 for indirect contact, and $\mathrm{B}=4.24,95 \% \mathrm{CI}$ : 3.02 to 5.45 for suspected contact).

According to the results presented in Tables 4 and 5, the overall IES-R scores were also significantly associated with the history of direct, indirect, or suspected contacts $(\mathrm{B}=4.89$, 95\% CI: 1.56 to 8.21 for direct contact, $\mathrm{B}=3.61,95 \% \mathrm{CI}$ : 1.27 to 5.94 for indirect contact, $\mathrm{B}=5.56,95 \% \mathrm{CI}: 3.30$ to 7.81 for suspected contact).

Likewise, there was no significant relationship between direct contact with a person with confirmed COVID-19 and the scores in the subscales of the IES-R $(p=0.072)$. However, such a relationship was observed with regard to the indirect $(p=0.031)$ and suspected contacts $(p<0.001)$. 
Table 3 Relationship between demographic variables and IES-R subscales (severity of PTSD) following COVID-19 outbreak

\begin{tabular}{|c|c|c|c|c|c|c|}
\hline Variables & Frequency & Normal & Partial PTSD & Probable PTSD & Immune system functioning & $P$ value \\
\hline \multicolumn{7}{|l|}{ Gender } \\
\hline Male & $778(72.4)$ & $244(31.4)$ & $160(20.6)$ & $78(10.0)$ & $296(38.0)$ & \multirow[t]{2}{*}{$0.000 * *$} \\
\hline Female & $297(27.6)$ & $145(49.0)$ & $57(19.3)$ & $20(6.8)$ & $74(25.0)$ & \\
\hline \multicolumn{7}{|l|}{ Age } \\
\hline $18-30$ & 309 (28.7) & $128(41.4)$ & $64(20.7)$ & $23(7.4)$ & $94(30.4)$ & \multirow[t]{5}{*}{$0.028 *$} \\
\hline $31-40$ & $442(41.1)$ & $146(33.1)$ & $91(20.6)$ & $33(7.5)$ & $171(38.8)$ & \\
\hline $41-50$ & $208(19.3)$ & $77(37.0)$ & $37(17.8)$ & $29(13.9)$ & $65(31.1)$ & \\
\hline $51-60$ & $95(8.8)$ & $30(31.6)$ & $18(18.9)$ & $13(13.7)$ & $34(35.8)$ & \\
\hline Over 60 & $21(2.0)$ & $8(38.1)$ & $7(33.3)$ & $0(0)$ & $6(28.6)$ & \\
\hline \multicolumn{7}{|l|}{ Children } \\
\hline Under 16 & $401(37.3)$ & $125(31.3)$ & $87(21.8)$ & $28(7.0)$ & $160(40.0)$ & \multirow[t]{4}{*}{$0.005 * *$} \\
\hline Over16 & $188(17.5)$ & $68(36.2)$ & $42(22.3)$ & $21(11.2)$ & $57(30.3)$ & \\
\hline Both & $113(10.5)$ & $48(42.5)$ & $11(9.7)$ & $15(13.3)$ & $39(34.5)$ & \\
\hline Childless & $373(34.7)$ & $148(39.7)$ & 77 (20.6) & $34(9.1)$ & $114(30.6)$ & \\
\hline \multicolumn{7}{|l|}{ Marital status } \\
\hline Single & $286(26.6)$ & $117(40.9)$ & $63(22.0)$ & $19(6.6)$ & $87(30.4)$ & \multirow[t]{4}{*}{0.205} \\
\hline Married & 751 (69.9) & $255(34.0)$ & $148(19.7)$ & $78(10.4)$ & $269(35.9)$ & \\
\hline Divorced & $34(3.2)$ & $15(44.1)$ & $6(17.6)$ & $1(2.9)$ & $12(35.3)$ & \\
\hline Deceased spouse & $4(0.4)$ & $2(50.0)$ & $0(0)$ & $0(0)$ & $2(50.0)$ & \\
\hline \multicolumn{7}{|l|}{ Family size } \\
\hline One & $22(2)$ & 7 (31.8) & $5(22.7)$ & $2(9.1)$ & 8 (36.4) & \multirow[t]{4}{*}{0.805} \\
\hline Two & $206(19.2)$ & $75(36.4)$ & $40(19.4)$ & $26(12.6)$ & 65 (31.6) & \\
\hline Three to four & 343 (31.9) & $127(37.0)$ & 64 (18.7) & $29(8.5)$ & $123(35.9)$ & \\
\hline Five and so & $504(46.9)$ & $180(35.8)$ & $108(21.5)$ & $41(8.2)$ & $174(34.6)$ & \\
\hline \multicolumn{7}{|l|}{ Occupation } \\
\hline Unemployed & $89(8.3)$ & $30(33.7)$ & $18(20.2)$ & $8(9.0)$ & $33(37.1)$ & \multirow[t]{7}{*}{0.195} \\
\hline Housewife & $300(27.9)$ & $89(29.7)$ & $59(19.7)$ & $37(12.3)$ & $115(38.3)$ & \\
\hline Student & 139 (12.9) & $61(43.9)$ & $34(24.5)$ & $5(3.6)$ & $39(28.1)$ & \\
\hline Medical Staff & $56(5.2)$ & $21(37.5)$ & $11(19.6)$ & $7(12.5)$ & $17(30.4)$ & \\
\hline Staff elsewhere & $291(27.1)$ & $109(37.5)$ & $57(19.6)$ & $26(8.9)$ & $99(34.0)$ & \\
\hline Worker & $131(12.2)$ & $55(42.3)$ & $23(17.7)$ & $8(6.2)$ & $44(33.8)$ & \\
\hline Healthcare worker & $69(6.4)$ & $24(34.8)$ & $15(21.7)$ & $7(10.1)$ & $23(33.3)$ & \\
\hline \multicolumn{7}{|l|}{ Education } \\
\hline Primary school & $9(0.8)$ & 8 (88.9) & $1(11.1)$ & $0(0)$ & $0(0)$ & \multirow[t]{4}{*}{$0.009 * *$} \\
\hline High school diploma & $220(20.5)$ & $73(33.3)$ & $47(21.5)$ & $16(7.3)$ & $83(37.9)$ & \\
\hline Bachelor's and Master's degrees & $722(67.2)$ & $259(35.9)$ & $135(18.7)$ & $72(10.0)$ & $256(35.5)$ & \\
\hline $\mathrm{PhD}$ & $124(11.5)$ & 49 (39.5) & 34 (27.4) & $10(8.1)$ & $31(25.0)$ & \\
\hline
\end{tabular}

*** Significant at 0.001 level, ** Significant at 0.01 level, * Significant at 0.05 level

\section{Relationship between DASS-21 and IES-R Scores, Beliefs about COVID-19, and Mental Health Status}

As presented in Table 6, individuals who believed that the deaths caused by COVID-19 were rising, obtained significantly higher scores in the stress subscale of the DASS-21 (B = 5.62, 95\% CI: 2.45 to 8.78$)$. In contrast, beliefs about the treatability of COVID-19 were significantly associated with lower scores in this subscale $(\mathrm{B}=-3.45,95 \% \mathrm{CI}:-5.20$ to $-1.70)$.
The respondents, who believed that the mortality induced by COVID-19 was increasing, also had significantly higher scores in the anxiety subscale of the DASS-21 ( $\mathrm{B}=2.85,95 \%$ CI: 0.34 to 5.36). On the contrary, beliefs about COVID-19 being treatable were significantly associated with lower anxiety scores $(\mathrm{B}=-2.64,95 \% \mathrm{CI}$ : -4.02 to -1.26$)$.

According to Tables 6 and 7, no significant relationship was observed between the scores in the subscales of the IES-R and the beliefs that COVID-19 was spreading ( $p=$ 0.103). However, a significant relationship was established 


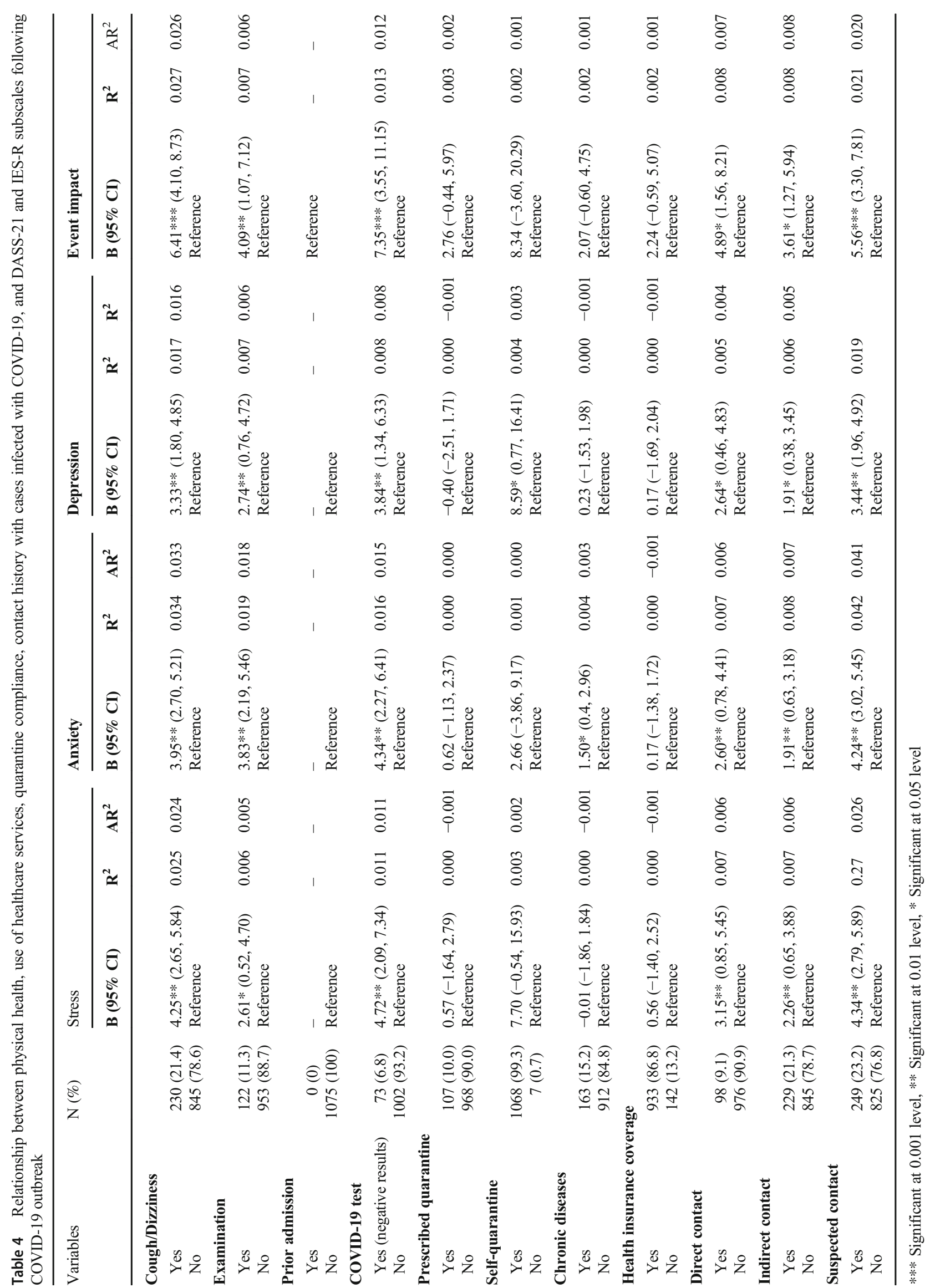


Table 5 Relationship between physical health, use of healthcare services, quarantine compliance, contact history with cases infected with COVID, and the IES-R subscales of (Severity of PTSD) following COVID-19 outbreak

\begin{tabular}{|c|c|c|c|c|c|c|}
\hline Variables & Frequency & Normal & Partial PTSD & Probable PTSD & Immune system functioning & $P$ value \\
\hline \multicolumn{7}{|l|}{ Cough/Dizziness } \\
\hline Yes & $230(21.4)$ & $56(24.3)$ & $37(16.1)$ & $23(10.0)$ & $114(49.6)$ & \multirow[t]{2}{*}{$0.000 * * *$} \\
\hline No & 845 (78.6) & $333(39.5)$ & $180(21.3)$ & $75(8.9)$ & $256(30.3)$ & \\
\hline \multicolumn{7}{|l|}{ Examination } \\
\hline Yes & $122(11.3)$ & $35(28.7)$ & $20(16.4)$ & $9(7.4)$ & $58(47.5)$ & \multirow[t]{2}{*}{$0.015^{*}$} \\
\hline No & $953(88.7)$ & $354(37.2)$ & $197(20.7)$ & $89(9.3)$ & $312(32.8)$ & \\
\hline \multicolumn{7}{|l|}{ Prior admission } \\
\hline Yes & $0(0)$ & $0(0)$ & $0(0)$ & $0(0)$ & $0(0)$ & \multirow[t]{2}{*}{-} \\
\hline No & $1075(100)$ & $389(36.2)$ & $217(20.2)$ & $98(9.1)$ & $370(34.5)$ & \\
\hline \multicolumn{7}{|l|}{ COVID-19 Test } \\
\hline Yes (Negative Results) & $73(6.8)$ & $16(21.9)$ & $14(19.2)$ & $5(6.8)$ & $38(52.1)$ & \multirow[t]{2}{*}{$0.008 * *$} \\
\hline No & $1002(93.2)$ & $373(37.3)$ & $203(20.3)$ & $93(9.3)$ & $332(33.2)$ & \\
\hline \multicolumn{7}{|l|}{ Prescribed quarantine } \\
\hline Yes & $107(10.0)$ & $34(31.8)$ & $21(19.6)$ & $9(8.4)$ & $43(40.2)$ & \multirow[t]{2}{*}{0.600} \\
\hline No & $968(90.0)$ & $355(36.7)$ & $196(20.3)$ & $89(9.2)$ & $327(33.8)$ & \\
\hline \multicolumn{7}{|l|}{ Self-quarantine } \\
\hline Yes & $1068(99.3)$ & $385(36.1)$ & $216(20.2)$ & $98(9.2)$ & $368(34.5)$ & \multirow[t]{2}{*}{0.640} \\
\hline No & $7(0.7)$ & $4(57.1)$ & $1(14.3)$ & $0(0)$ & $2(28.6)$ & \\
\hline \multicolumn{7}{|l|}{ Chronic diseases } \\
\hline Yes & $163(15.2)$ & $51(31.3)$ & $33(20.2)$ & $17(10.4)$ & $62(38.0)$ & \multirow[t]{2}{*}{0.500} \\
\hline No & $912(84.8)$ & $338(37.1)$ & $184(20.2)$ & $81(8.9)$ & $308(33.8)$ & \\
\hline \multicolumn{7}{|l|}{ Health insurance coverage } \\
\hline Yes & $933(86.8)$ & $320(34.3)$ & $197(21.1)$ & $89(9.5)$ & $326(35.0)$ & \multirow[t]{2}{*}{$0.008 * *$} \\
\hline No & $142(13.2)$ & 69 (48.6) & $20(14.1)$ & $9(6.3)$ & $44(31.0)$ & \\
\hline \multicolumn{7}{|l|}{ Direct contact } \\
\hline Yes & $98(9.1)$ & $25(25.5)$ & $19(19.4)$ & $10(10.2)$ & $44(44.9)$ & \multirow[t]{2}{*}{0.072} \\
\hline No & $976(90.9)$ & $364(37.3)$ & $198(20.3)$ & $88(9.0)$ & $326(33.4)$ & \\
\hline \multicolumn{7}{|l|}{ Indirect contact } \\
\hline Yes & $229(21.3)$ & $65(28.4)$ & $47(20.5)$ & $26(11.4)$ & $91(39.7)$ & \multirow[t]{2}{*}{$0.031 *$} \\
\hline No & 845 (78.7) & $324(38.3)$ & $170(20.1)$ & $72(8.5)$ & $279(33.0)$ & \\
\hline \multicolumn{7}{|l|}{ Suspected Contact } \\
\hline Yes & $249(23.2)$ & $63(25.3)$ & 48 (19.3) & $28(11.2)$ & $110(44.2)$ & \multirow[t]{2}{*}{$0.000 * * *$} \\
\hline No & $825(76.8)$ & $326(39.5)$ & $169(20.5)$ & $70(8.5)$ & $260(31.5)$ & \\
\hline
\end{tabular}

*** Significant at 0.001 level, ** Significant at 0.01 level, * Significant at 0.05 level

between these subscales and the beliefs in the treatability of COVID-19 $(p=0.001)$, and those about the fact that deaths caused by COVID-19 were growing $(p<0.001)$. The overall IES-R score was significantly higher in the individuals who believed in the increasing mortality rate of COVID-19 (B = 10.44, 95\% CI: 5.87 to 15.00$)$. In contrast, people who believed in the controllability of COVID-19 obtained significantly lower IES-R scores $(\mathrm{B}=-4.07,95 \% \mathrm{CI}:-6.61$ to $-1.52)$.

As shown in Table 6, the results for the stress subscale of the DASS-21 showed that the cases with a history of visiting a psychologist or a psychiatrist acquired significantly higher stress scores (B $=6.71,95 \%$ CI: 5.25 to 8.17$)$.

The results regarding the anxiety subscale of the DASS- 21 correspondingly demonstrated that people with a history of receiving treatment from a psychologist or a psychiatrist, having mental illnesses, or taking psychiatric medications also gained significantly higher anxiety scores $(\mathrm{B}=4.81,95 \%$ CI: 3.65 to $5.96, \mathrm{~B}=6.64,95 \% \mathrm{CI}: 4.94$ to 8.34 , and $\mathrm{B}=$ $4.70,95 \%$ CI: 2.91 to 6.49 , respectively). The overall IES-R scores for these variables were also significantly higher.

\section{Discussion}

This study investigated the levels of depression, anxiety, and stress, along with the psychological impact of COVID-19 in the individuals undergoing national quarantine from March 24 to April 10, 2020, in Mazandaran Province, Northern Iran. This web-based survey showed the high prevalence rates of 


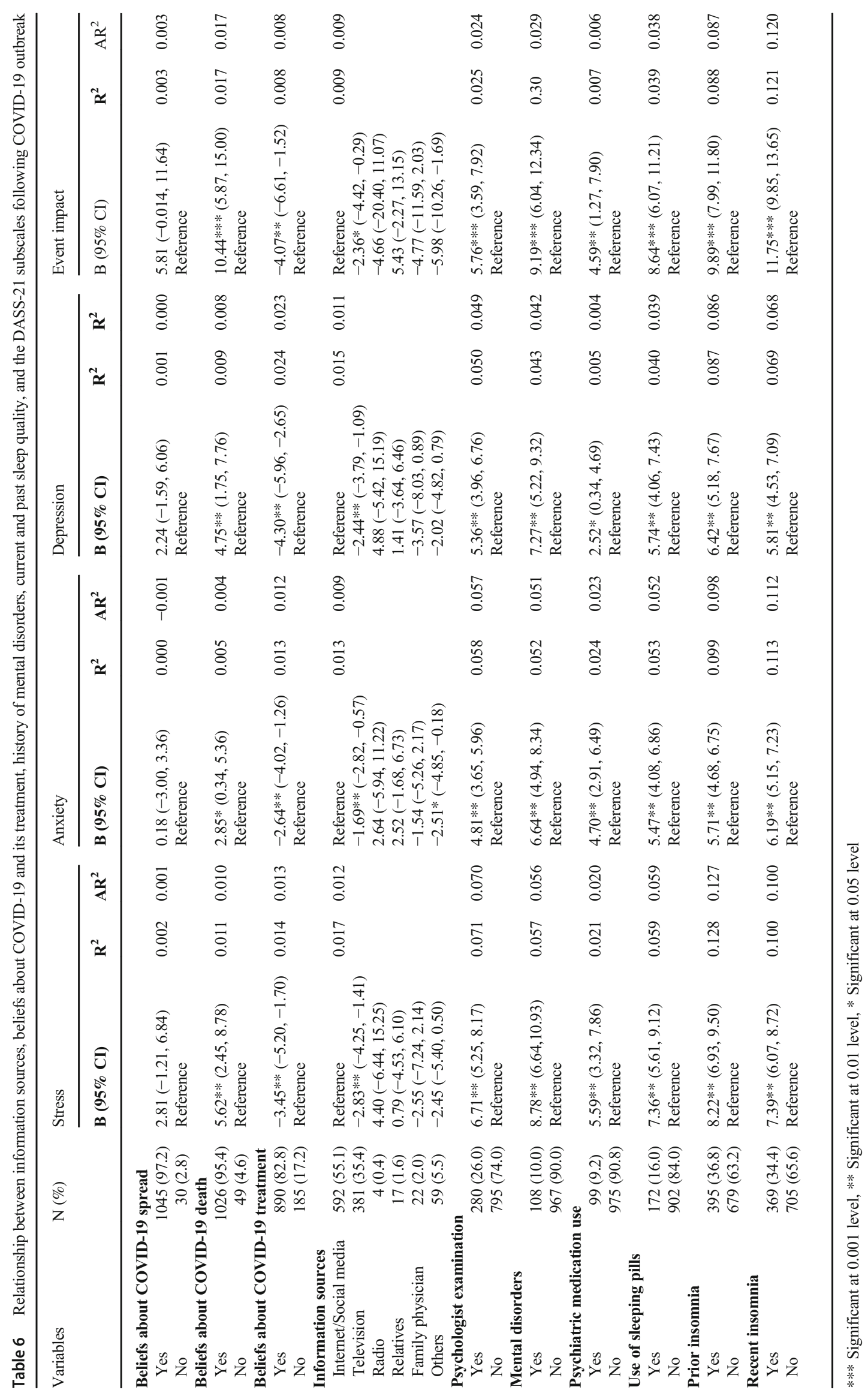


depression, anxiety, and stress, and the significant psychosocial impact of the given pandemic on the general population in this country during the nationwide COVID-19 quarantine. Of the eligible respondents, $22 \%$ of the cases had moderate-tosevere depression, $38.5 \%$ of the individuals were suffering from moderate-to-severe anxiety, and $47.2 \%$ of the respondents were experiencing moderate-to-severe stress. In 14.5\% of the cases, the psychosocial impact of the pandemic was classified as either probable or full PTSD to the point of immunosuppression. Previous studies had further shown that social distancing, to reduce the disease transmission, could considerably alter daily life routines, and have serious consequences for mental health and well-being in short and long term (Kinsinger et al., 2017).

Restricting the movement of people exposed to an infectious disease is called quarantine (The CDC, , 2020b). However, it is different from the isolation used to separate sick people (Manuell \& Cukor, 2011). In today's modern world, where people are rarely forced to undergo quarantine and social constraints, restrictive measures taken to control the pandemic can thus create a sense of hopelessness and insecurity among affected people and they may become weak and helpless under such conditions (Serafini et al., 2020). Social isolation, a sense of uncertainty about the future, and fear of new and unknown infectious agents, can further intensify abnormal anxiety (Khan et al., 2020). Anxiety may be also directly related to sensory deprivation and loneliness, in which an individual first suffers from insomnia, but later develops depression and PTSD (Torales et al., 2020). In addition to anxiety, negative impacts of the pandemic may include perceptions of low social support, separation from loved ones, loss of freedom, insecurity, and fatigue (Lee \& You, 2020). Psychological responses to the COVID-19 pandemic may also range from panic or a hysterical nervous breakdown (Barbisch et al., 2015) to a sense of hopelessness and depression, associated with negative outcomes such as suicidal behaviors (Thakur \& Jain, 2020). It is noteworthy that elevated anxiety may also have implications for other health measures (Rubin \& Wessely, 2020). In this respect, Zhang and Ma (2020), in their study in China, had stressed the need to pay much attention to mental health status in non-infected cases, as they were susceptible to be adversely affected by isolation and social distancing, due to the pandemic situation. They had further stated that it was reasonable to expect an increase in the incidence of severe mental disorders, during the current pandemic, although mental health disorders in some people may not reach the threshold required for a definitive diagnosis (Lima et al., 2020).

In contrast, Wang et al. (2011) had found no difference between quarantined and non-quarantined individuals in their study. The sample size was small and selected only from the students, which could influence the results. The survey by Milman et al. (2020) had also reported lower levels of anxiety among quarantined and non-quarantined individuals, but it was not clear whether the non-quarantined cases were forced to leave quarantine due to their occupation or voluntarily, which could result in anxiety.

In a survey by Huang and Zhao (2020), the overall prevalence rate of COVID-19-induced generalized anxiety disorder, depression symptoms, and sleep disorders in the general Chinese population had been correspondingly estimated to be $35.1 \%, 20.1 \%$, and $18.2 \%$, respectively. The tools used in the given study were the Generalized Anxiety Disorder-7 (GAD7), the Center for Epidemiologic Studies Depression (CES-D) scale, and the Pittsburgh Sleep Quality Index (PSQI). In a study conducted in Turkey, Özdin and Bayrak Özdin (2020) had reported that the prevalence rates of depression and anxiety during the COVID-19 pandemic, utilizing the Hospital Anxiety and Depression Scale (HADS) and the Health Anxiety Inventory (HAI), in a sample of 343 people, were equal to $23.6 \%$ and $45.1 \%$, respectively. Employing the Quality of Life (QOL) questionnaire, the GAD-7, and the Patient Health Questionnaire-9 (PHQ-9), Solomou and Constantinidou (2020) in a survey on a sample of 1642 people in Cyprus had found that $23.1 \%$ of these people had moderateto-severe anxiety and $9.2 \%$ of them were undergoing moderate depression. The discrepancies between the results, reported from countries across the globe, could be due to the use of different questionnaires together with the samples of different sizes.

In the present study, women were found to have higher levels of stress, anxiety, and depression compared with men. Although a few studies had observed no difference between men and women in this respect (Salari et al., 2020), the given findings were generally consistent with the results of extensive epidemiological studies conducted in the past, suggesting that women were at higher risks of psychological problems (Wang et al., 2020b; Noorbala \& Akhondzadeh, 2015; Gao et al., 2020; Lim et al., 2018). In the present study, individuals with a history of direct, indirect, or suspected contacts with an infected case also showed higher levels of stress, anxiety, and depression. Naturally, people with a history of contacts with infected cases are concerned about being infected, which results in increased levels of stress and anxiety.

This study revealed that the psychosocial impact of the pandemic was severe to the point of immunosuppression in a significant proportion of the respondents. In one study, the prevalence rates of depression, anxiety, and symptoms of PTSD, during and after the outbreak of SARS, had been also reported to range from 10 to $18 \%$ (Wu et al., 2005). Among the groups of people with different levels of education, those holding high school diplomas had the highest percentage of PTSD to the point of immunosuppression. Encountering an unknown threat could thus weaken the immune system by making individuals anxious, and insufficient information could exacerbate this problem (Bajema et al., 2020). Anxiety 
could also undermine the ability to distinguish between reliable and unreliable information, making individuals exposed to false news and information (To et al., 2020).

In the present study, beliefs that deaths caused by COVID19 were on the rise, were associated with a higher level of stress, anxiety, and depression; and conversely, beliefs about the treatability of this condition were associated with a lower level of stress, anxiety, and depression. Accordingly, no stress, anxiety, or depression was observed in the cases who did not believe in the COVID-19 pandemic, but this could be a warning sign that these individuals might not take the issue seriously to comply with the protocols. In addition, the cause of increased stress, anxiety, and depression in the people with the beliefs mentioned earlier could be hypochondriac concerns (Furer et al., 1997) and fears that pandemics were difficult to control.

A significant relationship was also found between a history of receiving treatment from a psychologist or a psychiatrist, having mental illnesses, and taking psychiatric medications, and higher levels of stress, anxiety, and depression, and suffering from more severe psychosocial impact induced by COVID-19. According to a study conducted in Australia, during the COVID-19 pandemic, cases with mood disorders had experienced greater psychological anxiety than those without mental problems, and the cases with bipolar disorders had faced greater stress and depression intensification than ones with major depressive disorder (Van Rheenen et al., 2020).

Table 7 Relationship between information sources, beliefs about COVID-19 and its treatment, history of mental disorders, current and past sleep quality, and IES-R subscales (Severity of PTSD) following COVID-19 outbreak

\begin{tabular}{|c|c|c|c|c|c|c|}
\hline Variables & Frequency & Normal & Partial PTSD & Probable PTSD & Immune System Functioning & P Value \\
\hline \multicolumn{7}{|c|}{ Beliefs about COVID-19 spread } \\
\hline Yes & $1045(97.2)$ & $374(35.8)$ & $209(20.0)$ & $98(9.4)$ & $363(34.8)$ & \multirow[t]{2}{*}{0.103} \\
\hline No & $30(2.8)$ & $15(50.0)$ & $8(26.7)$ & $0(0)$ & $7(23.3)$ & \\
\hline \multicolumn{7}{|c|}{ Beliefs about COVID-19 death } \\
\hline Yes & $1026(95.4)$ & $357(34.8)$ & $209(20.4)$ & $95(9.3)$ & $364(35.5)$ & \multirow[t]{2}{*}{$0.000 * * *$} \\
\hline No & 49 (4.6) & $32(65.3)$ & $8(16.3)$ & $3(6.1)$ & $6(12.2)$ & \\
\hline \multicolumn{7}{|c|}{ Beliefs about COVID-19 treatment } \\
\hline Yes & $890(82.8)$ & $327(36.7)$ & $196(22.0)$ & $81(9.1)$ & $289(32.1)$ & \multirow[t]{2}{*}{$0.001 * * *$} \\
\hline No & $185(17.2)$ & $62(33.7)$ & $21(11.4)$ & $17(9.2)$ & $84(45.7)$ & \\
\hline \multicolumn{7}{|l|}{ Information sources } \\
\hline Internet/Social media & $592(55.1)$ & $198(33.5)$ & $121(20.5)$ & $52(8.8)$ & $220(37.2)$ & \multirow[t]{6}{*}{0.064} \\
\hline Television & $381(35.4)$ & $149(39.1)$ & $76(19.9)$ & $35(9.2)$ & $121(31.8)$ & \\
\hline Radio & $4(0.4)$ & $3(75.0)$ & $0(0)$ & $0(0)$ & $1(25.0)$ & \\
\hline Relatives & $17(1.6)$ & $3(17.6)$ & $2(11.8)$ & $4(23.5)$ & $8(47.1)$ & \\
\hline Family physician & $22(2.0)$ & $8(36.4)$ & $7(31.8)$ & $4(18.2)$ & $3(13.6)$ & \\
\hline Others & $59(5.5)$ & $28(47.5)$ & $11(18.6)$ & $3(5.1)$ & $17(28.8)$ & \\
\hline \multicolumn{7}{|l|}{ Psychologist examination } \\
\hline Yes & $280(26.0)$ & $83(29.6)$ & $42(15.0)$ & $19(6.8)$ & $136(48.6)$ & \multirow[t]{2}{*}{$0.000 * * *$} \\
\hline No & $795(74.0)$ & $306(38.5)$ & $175(22.0)$ & $79(9.9)$ & $234(29.5)$ & \\
\hline \multicolumn{7}{|l|}{ Mental disorder } \\
\hline Yes & $108(10.0)$ & $19(17.6)$ & $18(16.7)$ & $7(6.5)$ & $64(59.3)$ & \multirow[t]{2}{*}{$0.000 * * *$} \\
\hline No & $967(90.0)$ & $370(38.3)$ & 199 (20.6) & $91(9.4)$ & $306(31.7)$ & \\
\hline \multicolumn{7}{|c|}{ Psychiatric medication use } \\
\hline Yes & $99(9.2)$ & $26(26.3)$ & $14(14.1)$ & $11(11.1)$ & $48(48.5)$ & \multirow[t]{2}{*}{$0.009 * *$} \\
\hline No & $975(90.8)$ & $363(37.2)$ & $203(20.8)$ & $87(8.9)$ & $322(33.0)$ & \\
\hline \multicolumn{7}{|l|}{ Use of sleeping pills } \\
\hline Yes & $172(16.0)$ & $39(22.7)$ & $27(15.7)$ & $11(6.4)$ & $95(55.2)$ & \multirow[t]{2}{*}{$0.000 * * *$} \\
\hline No & $902(84.0)$ & $350(38.8)$ & $190(21.1)$ & $87(9.6)$ & $275(30.5)$ & \\
\hline \multicolumn{7}{|l|}{ Prior insomnia } \\
\hline Yes & $395(36.8)$ & $84(21.3)$ & $81(20.5)$ & $32(8.1)$ & $198(50.1)$ & \multirow[t]{2}{*}{$0.000 * * *$} \\
\hline No & $679(63.2)$ & 305 (44.9) & $136(20.0)$ & $66(9.7)$ & $172(25.3)$ & \\
\hline \multicolumn{7}{|l|}{ Recent insomnia } \\
\hline Yes & $369(34.4)$ & $65(17.6)$ & $76(20.6)$ & $35(9.5)$ & $193(52.3)$ & \multirow[t]{2}{*}{$0.000 * * *$} \\
\hline No & 705 (65.6) & $324(46.0)$ & $141(20.0)$ & $63(8.9)$ & $177(25.1)$ & \\
\hline
\end{tabular}

*** Significant at 0.001 level, $* *$ Significant at 0.01 level 
In the present study, respondents having children aged under 16 had much higher levels of stress and anxiety than those with children over 16 years of age or without children. As reported, people with younger children were more likely to be afraid of infection with the virus (Braunack-Mayer et al., 2020). Since social communications are completely influenced by the news feeds of the pandemic, children are exposed to large volumes of information about this subject. At the same time, children observe high levels of stress and anxiety among adults around them and experience fundamental changes in their daily routines and social structures (Dalton et al., 2020). According to a study by Sprang and Silman (2013), children undergoing isolation or quarantine, because of a pandemic, were more likely to develop acute stress disorder, adjustment disorder, and grief. It is thus possible that sensing such psychological problems in children and being concerned about their inability to provide sufficient care intensify the levels of stress and anxiety in parents.

In this study, people with a history of chronic illnesses showed higher levels of anxiety during the pandemic. Similar surveys had further established that a history of chronic diseases could make people more subjected to stress, depression, and anxiety during a pandemic (Zhu et al., 2020). Since individuals with chronic diseases have a higher risk of death from COVID-19, worries and fears of contracting the virus could increase the levels of anxiety and stress in these cases. This study also found that people with higher IES-R scores were more likely to report sleep disorders during the COVID-19 pandemic. In this sense, other surveys had reported significantly reduced sleep quality because of the PTSD associated with the COVID-19 pandemic (Zhang et al., 2020a). Prolonged isolation, fear of disease transmission, frustration, fatigue, shortage of personal protective equipment, insufficient information, financial problems due to business closures, and negative rumors and beliefs could thus cause or exacerbate sleep problems (Serafini et al., 2020; Huang \& Zhao, 2020; Solomou \& Constantinidou, 2020).

\section{Limitations and Future Research Perspective}

Among the limitations of this study was that the data were extracted through a cross-sectional research design. As well, the self-report measures of the DASS-21 and the IES-R subscales might not be consistent with the assessments conducted by mental health professionals. Another limitation was that only literate cases, having access to the Internet, were surveyed, so these groups may not represent the whole society (since this study was conducted during the COVID-19 pandemic, a web-based survey method was used to avoid contributing to the disease transmission); therefore, the results could be indeed biased. Moreover, it was not possible to assess the mental health status of the participants before being affected because of the sudden spread of the pandemic. As the statistical population recruited in this study did not include people infected with COVID-19, further surveys on this population are highly recommended.

As the quarantine rules and the resulting restricted access to face-to-face communications and traditional psychosocial interventions can have serious impacts on vulnerable people (Zhang et al., 2020b), healthcare officials are recommended to turn to psychological training and interventions provided on smartphones, web platforms, or television. Simultaneously, mental health professionals need to prepare psychosocial interventions and support plans for the general population.

\section{Conclusion}

The results of this study, conducted during the first peak of the COVID-19 pandemic in Iran, showed that about half of the respondents had moderate-to-severe stress, one-third of them were suffering from moderate-to-severe anxiety, and onequarter of these individuals were undergoing moderate-tosevere depression. As well, the psychosocial impact of COVID-19 was significant enough to be classified as either probable or full PTSD to the point of immunosuppression in one-fifth of the cases. The findings can thus serve as a basis for planning preventive measures and psychosocial interventions during pandemics.

Acknowledgements The authors express their gratitude toward the financially supportive organizations such as Mazandaran University of Medical Sciences.

Author's Contribution Maryam Hasannezhad Reskati did the literature search, drafting the manuscript, data gathering and editing the manuscript. Misagh Shafizad \& Akbar Hedayatizadeh-Omran \& Sahar Khosravi contributed in editing the manuscript. Forouzan Elyasi contributed in the conception of the work, study design and writing of the protocol, collected the data and editing the manuscript.

Funding This research was supported financially by Mazandaran University of Medical Sciences. (Grant Number:7308)

Data Availability The data that support the findings of this study are available from the corresponding author upon reasonable request.

Our study obtained the approval of the Research Ethics Committee of Mazandaran University of Medical Sciences, the approval of which has been published on the website of the National Ethics Committee (IR.MAZUMS.REC.1399.001).

\section{Declarations}

Conflict of Interests The authors have no conflicts of interest relevant to this article. 


\section{References}

Asukai, N., Kato, H., Kawamura, N., Kim, Y., Yamamoto, K., Kishimoto, J., Miyake, Y., \& Nishizono-Maher, A. (2002). Reliability and validity of the Japanese-language version of the impact of event scale-revised (IES-RJ): Four studies of different traumatic events. The Journal of nervous and mental disease, 190(3), 175-182. https://doi.org/10.1097/00005053-200203000-000006.

Bajema, K. L., Oster, A. M., McGovern, O. L., Lindstrom, S., Stenger, M. R., Anderson, T. C., Isenhour, C., Clarke, K. R., Evans, M. E., Chu, V. T., Biggs, H. M., Kirking, H. L., Gerber, S. I., Hall, A. J., Fry, A. M., \& Oliver, S. E. (2020). Persons evaluated for 2019 Novel coronavirus- United States, January 2020. MMWR Morb Mortal Wkly Rep, 69, 166-170. 10.15585/MMWR.mm6906e1.

Barbisch, D., Koenig, K. L., \& Shih, F. Y. (2015). Is there a case for quarantine? Perspectives from to Ebola. Disaster Medicine and Public Health Preparedness, 9, 547-553. https://doi.org/10.1017/ dmp.2015.38.

Braunack-Mayer, A., Tooher, R., Collins, J. E., Street, J. M., \& Marshall, H. (2020). Understanding the school community's response to school closures during the H1N1 2009 influenza pandemic. BMC Public Health, 15(13), 344. https://doi.org/10.1186/1471-2458-13344.

Brown, T. A., Chorpita, B. F., Korotitsch, W., \& Barlow, D. H. (1997). Psychometric properties of the depression anxiety stress scales (DASS) in clinical samples. Behaviour Research and Therapy, 35(1), 79-89. https://doi.org/10.1016/s0005-7967(96)00068-x.

Centers for Disease Control and Prevention. (2020a). Symptoms Of Novel Coronavirus (2019-Ncov). https://www.cdc.gov/ coronavirus/2019-ncov/about/symptoms.html

Centers for Disease Control and Prevention. (2020b). Quarantine and isolation 2017. https:// www .cdc .gov/ quarantine/index.html.

Chang, M. C., \& Park, D. (2020). Incidence of post-traumatic stress disorder after coronavirus disease. Healthcare, 8(4), 373. https:// doi.org/10.3390/healthcare8040373.

Creamer, M., Bell, R., \& Failla, S. (2003). Psychometric properties of the impact of event scale revised. Behaviour Research and Therapy, 41(12), 1489-1496. https://doi.org/10.1016/j.brat.2003.07.010.

Czeisler, M. É., Lane, R. I., Petrosky, E., Wiley, J. F., Christensen, A., Njai, R., Weaver, M. D., Robbins, R., Facer-Childs, E. R., Barger, L. K., Czeisler, C. A., Howard, M. E., \& Rajaratnam, S. (2020). Mental health, substance use, and suicidal ideation during the COVID-19 pandemic - United States, June 24-30, 2020. MMWR. Morbidity and Mortality Weekly Report, 69(32), 1049-1057. https:// doi.org/10.15585/mmwr.mm6932a1.

Dalton, L., Rapa, E., \& Stein, A. (2020). Protecting the psychological health of children through effective communication about COVID19. Lancet Child Adolesc Health, 4(5), 346-347. https://doi.org/10. 1016/S2352-4642(20)30097-3 Epub 2020 Mar 31.

Danese, A., Smith, P., Chitsabesan, P., \& Dubicka, B. (2020). Child and adolescent mental health amidst emergencies and disasters. The British Journal of Psychiatry, 216(3), 159-162. https://doi.org/10. 1192/bjp.2019.244.

Doshmangir, L., Mahbub Ahari, A., Qolipour, K., Azami-Aghdash, S., Kalankesh, L., Doshmangir, P., Mobasseri, K., \& KhodayariZarnaq, R. (2020). East Asia's strategies for effective response to COVID-19: Lessons learned for Iran. Management Strategies in Health System, 4(4), 370-373 http://mshsj.ssu.ac.ir/article-1-332en.html.

Dutheil, F., Mondillon, L., \& Navel, V. (2020). PTSD as the second tsunami of the SARS-Cov-2 pandemic. Psychological Medicine, 1-2. https://doi.org/10.1017/S0033291720001336.

Fekih-Romdhane, F., Ghrissi, F., Abbassi, B., Cherif, W., \& Cheour, M. (2020). Prevalence and predictors of PTSD during the COVID-19 pandemic: Findings from a Tunisian community sample. Psychiatry Research, 290, 113131.

Forte, G., Favieri, F., Tambelli, R., \& Casagrande, M. (2020). COVID-19 pandemic in the Italian population: Validation of a post-traumatic stress disorder questionnaire and prevalence of PTSD symptomatology. International Journal of Environmental Research and Public Health, 17(11), 4151.

Furer, P., Walker, J. R., Chartier, M. J., \& Stein, M. B. (1997). Hypochondriacal concerns and somatization in panic disorder. Depress Anxiety, 6, 78-85. https://doi.org/10.1002/(SICI)15206394(1997)6:2<78:AID-DA4>3.0.CO;2-1.

Gao, W., Ping, S., \& Liu, X. (2020). Gender differences in depression, anxiety, and stressamong college students: A longitudinal study from China. J. Affect Disord, 263, 292-300. https://doi.org/10. 1016/j.jad.2019.11.121.

González-Sanguino, C., Ausín, B., Castellanos, M. Á., Saiz, J., LópezGómez, A., Ugidos, C., \& Muñoz, M. (2020). Mental health consequences during the initial stage of the 2020 coronavirus pandemic (COVID-19) in Spain. Brain Behav Immun, 87, 172-176. https:// doi.org/10.1016/j.bbi.2020.05.040.

Huang, Y., \& Zhao, N. (2020). Generalized anxiety disorder, depressive symptoms and sleep quality during COVID-19 outbreak in China: A web-based cross-sectional survey. Psychiatry Research, 288, 112954. https://doi.org/10.1016/j.psychres.2020.112954.

Kawamura, N., Kim, Y., \& Asukai, N. (2001). Suppression of cellular immunity in men with a past history of post-traumatic stress disorder. Am J Psychiatry, 158(3), 484-486. https://doi.org/10.1176/ appi.Ajp.158.3.484.

Khan, S., Siddique, R., Li, H., Ali, A., Shereen, M. A., Bashir, N., \& Xue, M. (2020). Impact of coronavirus outbreak on psychological health. J. Glob Health, 10(1), 010331. https://doi.org/10.7189/jogh.10. 010331.

Kinsinger, L. S., Anderson, C., Kim, J., Larson, M., Chan, S. H., King, H. A., Rice, K. L., Slatore, C. G., Tanner, N. T., Pittman, K., \& Monte, R. J. (2017). Implementation of lung cancer screening in the Veterans Health Administration. JAMA internal medicine, 117(3), 399-406. https://doi.org/10.1001/jamainternmed.2016.9022.

Krishnamoorthy, Y., Nagarajan, R., Saya, G. K., \& Menon, V. (2020). Prevalence of psychological morbidities among general population, healthcare workers and COVID-19 patients amidst the COVID-19 pandemic: A systematic review and meta-analysis. Psychiatry Research, 293, 113382. https://doi.org/10.1016/j.psychres.2020. 113382.

Manuell, M. E., \& Cukor, J. (2011). Mother nature versus human nature: Public compliance with evacuation and quarantine. Disasters, 35(2), 417-442. https://doi.org/10.1111/j.1467-7717.2010.01219.x Epub 2010 Nov 15.

Moghanibashi-Mansourieh, A. (2020a). Assessing the anxiety level of Iranian general population during COVID-19 outbreak. Asian Journal of Psychiatry, 51, 102076.

Lee, S. H., Shin, H. S., Park, H. Y., Kim, J. L., Lee, J. J., Lee, H., Won, S. D., \& Han, W. (2019). Depression as a mediator of chronic fatigue and post-traumatic stress symptoms in Middle East respiratory syndrome survivors. Psychiatry investigation, 16(1), 59-64. https://doi. org/10.30773/pi.2018.10.22.3.

Lee, M., \& You, M. (2020). Psychological and behavioral responses in South Korea during the early stages of coronavirus disease 2019 (COVID-19). International Journal of Environmental Research and Public Health, 17(9), 2977. https://doi.org/10.3390/ ijerph17092977.

Leung, G. M., Lam, T. H., Ho, L. M., Ho, S. Y., Chan, B. H., Wong, I. O., \& Hedley, A. J. (2003). The impact of community psychological responses on outbreak control for severe acute respiratory syndrome in Hong Kong. J. Epidemiology \& Community Health, 57(11), 857863. https://doi.org/10.1136/jech.57.11.857. 
Leung, G. M., Quah, S., Ho, L. M., Ho, S.Y., Hedley, A. J., Lee, H. P., \& Lam, T.H. (2009). Community psycho-behavioural surveillance and related impact on outbreak control in Hong Kong and Singapore during the SARS epidemic. Hong Kong Medical Journal, 15(9), 30-4. PMID: 20393223.

Lima, C. K. T., Carvalho, P. M. M., Lima, I. A. A. S., Nunes, J. V. A. O., Saraiva, J. S., de Souza, R. I., da Silva, C. G. L., \& Neto, M. L. R. (2020). The emotional impact of Coronavirus 2019-nCoV (new Coronavirus disease). Psychiatry Res, 287, 112915. https://doi.org/ 10.1016/j.psychres.2020.112915.

Lim, G. Y., Tam, W. W., Lu, Y., Ho, C. S., Zhang, M. W., \& Ho, R. C. (2018). Prevalence of depression in the community from 30 countries between 1994 and 2014. Scientific Reports, 8, 2861. https://doi. org/10.1038/s41598-018-21243-x.

Moghanibashi-Mansourieh, A. (2020b). Assessing the anxiety level of Iranian general population during COVID-19 outbreak. Asian Journal of Psychiatry, 51, 102076. https://doi.org/10.1016/j.ajp. 2020.102076.

Milman, E., Lee, S. A., \& Neimeyer, R. A. (2020). Social isolation as a means of reducing dysfunctional coronavirus anxiety and increasing psychoneuroimmunity. Brain, Behavior, and Immunity, 87, 138139. https://doi.org/10.1016/j.bbi.2020.05.007.

Noorbala, A. A., \& Akhondzadeh, S. (2015). Mental health study process into prevalence of mental disorders in Iran. Archives of Iranian Medicine, 18(2), 74-75.

Novel, C. P. E. R. E. (2020). The epidemiological characteristics of an outbreak of 2019 novel coronavirus diseases (COVID-19) in China. Zhonghua liu xing bing xue za zhi= Zhonghua liuxingbingxue zazhi, 41(2), 145. https://doi.org/10.3760/cma.j.issn.0254-6450.2020.02. 003.

Özdin, S., \& Bayrak Özdin, Ș. (2020). Levels and predictors of anxiety, depression and health anxiety during COVID-19 pandemic in Turkish society: The importance of gender. The International Journal of Social Psychiatry, 66(5), 504-511. https://doi.org/10. 1177/0020764020927051.

Panaghi, L., Hakim Shooshtari, M., \& Atari Mogadam, J. (2006). Persian version validation in impact of event scale-revised. Tehran Univ Med J, 64(3), 52-60 http://tumj.tums.ac.ir/article-1-974-en.html.

Park, H. Y., Park, W. B., Lee, S. H., Kim, J. L., Lee, J. J., Lee, H., \& Shin, H. S. (2020). Post-traumatic stress disorder and depression of survivors 12 months after the outbreak of Middle East respiratory syndrome in South Korea. BMC Public Health, 20(605), 1-9. https:// doi.org/10.1186/s12889-020-08726-1.

Rubin, G. J., Potts, H. W., \& Michie, S. (2010). The impact of communications about swine flu (influenza A H1N1v) on public responses to the outbreak: Results from 36 national telephone surveys in the UK. Health Technology Assessment, 14(34), 183-266. https://doi. org/10.3310/hta14340-03.

Rubin, G. J., \& Wessely, S. (2020). Coronavirus: The psychological effects of quarantining a city. BMJ Opinion, 368, m313. https:// doi.org/10.1136/bmj.m313.

Sahebi, A., Asghari, M. J., \& Salari, R. S. (2005). Validation of depression anxiety and stress scale (DASS-21) for an Iranian population. Iranian Psychologists, 4(1), 299-313 http://jip.azad.ac.ir/article_ 512443_a0d2c015073fc1d62ef524cc2302c4f0.pdf?lang=en.

Salari, N., Hosseinian-Far, A., Jalali, R., Vaisi-Raygani, A., Rasoulpoor, S., Mohammadi, M., Rasoulpoor, S., \& Khaledi-Paveh, B. (2020). Prevalence of stress, anxiety, depression among the general population during the COVID-19 pandemic: A systematic review and meta-analysis. Globalization and Health, 16(1), 57. https://doi.org/10. 1186/s12992-020-00589-w.

Seddighi, H., Dollard, M. F., \& Salmani, I. (2020). Psychosocial safety climate of employees during the COVID-19 pandemic in Iran: A policy analysis. Disaster Medicine and Public Health Preparedness, 1-7. https://doi.org/10.1017/dmp.2020.370.
Serafini, G., Parmigiani, B., Amerio, A., Aguglia, A., Sher, L., \& Amore, M. (2020). The psychological impact of COVID-19 on the mental health in the general population, QJM. International Journal of Medicine, 113(8), 531-537. https://doi.org/10.1093/qjmed/ hcaa201.

Solomou, I., \& Constantinidou, F. (2020). Prevalence and predictors of anxiety and depression symptoms during the COVID-19 pandemic and compliance with precautionary measures: Age and sex matter. Int. J. Environ. Res. Public Health, 17(14), 4924. https://doi.org/10. 3390/ijerph17144924.

Sprang, G., Silman, M. (2013). Posttraumatic stress disorder in parents and youth after health-related disasters. Disaster Med Public, 7(1), 105-110. https://doi.org/10.1017/dmp.2013.22.

Sun, L., Sun, Z., Wu, L., Zhu, Z., Zhang, F., Shang, Z., Jia, Y., Gu, J., Zhou, Y., Wang, Y., Liu, N., Liu, W. (2020). Prevalence and risk factors of acute post-traumatic stress symptoms during the COVID19 outbreak in Wuhan, China. MedRxiv. https://doi.org/10.1101/ 2020.03.06.2003 2425 .

Thakur, V., \& Jain, A. (2020). COVID 2019-suicides: a global psychological pandemic. Brain Behavior Immun, 88, 952-953. https://doi. org/10.1016/j.bbi.2020.04.062.

Thibodeau, M. A., Welch, P. G., Sareen, J., \& Asmundson, G. J. G. (2013). Anxiety disorders are independently associated with suicide ideation and attempts: Propensity score matching in two epidemiological samples:Anxiety disorders and suicide. Depression and Anxiety, 30, 947-954. 10.02/da.22203.

To, K. K., Tsang, O. T., Yip, C. C., Chan, K. H., Wu, T. C., Chan, J. M., Leung, W. S., Chik, T. S., Choi, C. Y., Kandamby, D. H., Lung, D. C., Tam, A. R., Poon, R. W., Fung, A. Y., Hung, I. F., Cheng, V. C., Chan, J. F., \& Yuen, K. Y. (2020). Consistent detection of 2019 Novel coronavirus in saliva. Clinical Infectious Diseases, 71(15), 841-843. https://doi.org/10.1093/cid/ciaa149.

Torales, J., O’Higgins, M., Castaldelli-Maia, J. M., \& Ventriglio, A. (2020). The outbreak of COVID-19 coronavirus and its impact on global mental health. The International Journal of Social Psychiatry, 66(4), 317-320. https://doi.org/10.1177/ 0020764020915212.

Van Rheenen, T. E., Meyer, D., Neill, E., Phillipou, A., Tan, E. J., Toh, W. L., \& Rossell, S. L. (2020). Mental health status of individuals with a mood-disorder during the COVID-19 pandemic in Australia: Initial results from the COLLATE project. J. Affect Disord, 275, 6977. https://doi.org/10.1016/j.jad.2020.06.037.

Wang, Y., Xu, B., Zhao, G., Cao, R., He, X., \& Fu, S. (2011). Is quarantine related to immediate negative psychological consequences during the 2009 H1N1 epidemic? General Hospital Psychiatry, 33(1), 75-77. https://doi.org/10.1016/j.genhosppsych.2010.11.001.

Wang, Y. X., Guo, H. T., Du, X. W., Song, W., Lu, C., \& Hao, W. N. (2020a). Factors associated with post-traumatic stress disorder of nurses exposed to corona virus disease 2019 in China. Medicine, 99(26), e20965. https://doi.org/10.1097/MD.0000000000020965.

Wang, C., Pan, R., Wan, X., Tan, Y., Xu, L., Ho, C. S., \& Ho, R. C. (2020b). Immediate psychological responses and associated factors during the initial stage of the 2019 coronavirus disease (COVID-19) epidemic among the general population in China. Int. J. Environ. Res. Public Health, 17(5), 1729. https://doi.org/10.3390/ ijerph17051729.

World Health Organization. (2020a). WHO director-General's opening remarks at the media briefing on COVID-19 - 11 March 2020. https://www.who.int/dg/speeches/detail/who-director-generalsopening-remarks-at-the-media-briefing-on-covid-19\%2D\%2D-11march-2020.

World Health Organization. (2020b). Coronavirus disease (COVID-19). https://www.who.int/emergencies/diseases/novel-coronavirus2019/situation-reports.

World Health Organization. (2020c). Considerations for quarantine of individuals in the context of containment for coronavirus disease 
(COVID-19): Interim guidance, 29 February 2020. World Health Organization. https://apps.who.int/iris/handle/10665/331299

Wu, K. K., Chan, S. K., \& Ma, T. M. (2005). Post-traumatic stress, anxiety, and depression in survivors of severe acute respiratory syndrome (SARS). Journal of Traumatic Stress, 18(1), 39-42. https:// doi.org/10.1002/jts.20004.

Yavarian, J., Shafiei-Jandaghi, N. Z., Sadeghi, K., Shatizadeh Malekshahi, S., Salimi, V., Nejati, A., Aja-Minejad, F., Ghavvami, N., Saadatmand, F., Mahfouzi, S., Fateminasab, G., Parhizgari, N., Ahmadi, A., Razavi, K., Ghabeshi, S., Saberian, M., Zanjani, E., Namazi, F., Shahbazi, T., Rezaie F., ... Mokhtari Azad T. (2020). First Cases of SARS-CoV-2 in Iran, 2020: Case Series Report. Iranian Journal of Public Health, 49(8), 1564. https://doi.org/10. 18502/ijph.v49i8.3903. PMID: 33083334; PMCID: PMC7554384.

Yildirim, H., Işik, K., \& Aylaz, R. (2021). The effect of anxiety levels of elderly people in quarantine on depression during covid-19 pandemic. Social Work in Public Health, 36(2), 194-204. https://doi.org/10. 1080/19371918.2020.1868372.

Zhang, Y., \& Ma, Z. F. (2020). Impact of the COVID-19 pandemic on mental health and quality of life among local residents in Liaoning Province, China: A cross-sectional study. Int. J. Environ. Res. Public Health, 17(7), 2381. https://doi.org/10.3390/ ijerph17072381.
Zhang, F., Shang, Z., Ma, H., Jia, J., Sun, L., Guo, X., Wu, L., Sun, Z., Zhou, Y., Wang, Y., Liu, N., \& Liu, W. (2020a). High risk of infection caused post-traumatic stress symptoms in individuals with poor sleep quality: A study on influence of coronavirus disease (COVID-19) in China. medRxiv. https://doi.org/10.1101/2020.03. 22.20034504.

Zhang, J., Wu, W., Zhao, X., \& Zhang, W. (2020b). Recommended psychological crisis intervention response to the 2019 novel coronavirus pneumonia outbreak in China: A model of West China hospital. Precision Clinical Medicine, 3(1), 3-8. https://doi.org/10. 1093/pcmedi/pbaa006.

Zhu, Z., S, X. U., Wang, H., Liu, Z., Wu, J., Li, G., Miao, J., Zhang, C., Yang, Y., Sun, W., Zhu, S., Fan, Y., Chen, Y., Hu, J., Liu, J., \& Wang, W. (2020). COVID-19 in Wuhan: Sociodemographic characteristics and hospital support measures associated with the immediate psychological impact on healthcare workers. EClinical Medicine, 24, 100443. https://doi.org/10.1016/j.eclinm.2020. 100443.

Publisher's Note Springer Nature remains neutral with regard to jurisdictional claims in published maps and institutional affiliations. 